Congress under the Education Council Act 1991) has issued a scathing review of the way US schools have dropped core academic subjects in order to fit intellectually marginal courses, such as sex education and parenting, into the school day. The commission says US schools have followed an unspoken rule that says: "learn what you can in the time we make available". That implies that students too often graduate without learning what they need to know in history, science, mathematics, even the English language.

US schools typically provide only $5^{\circ}$ hours of classroom time a day, and for a mere 180 days a year. (The schedule derives from the previous century, when students had to get home to work on the family farm.) This outmoded educational pattern compares unfavourably with that in Germany, France, Britain and Japan. In Germany, for instance, the total time devoted to the study of core subjects is 3,528 hours a year, but in the United States it is only 1,460 hours. Furthermore, the commission found an important difference in attitude between school systems in the United States and elsewhere. Bluntly put, it says that "in Germany and Japan, learning matters." By contrast, social problems (particularly in the inner cities) have turned too many US schools into the equivalent of day-care centres.

Just as the National Commission published its analysis of US schools generally, together with its sweeping recommendation for altering the pattern of US society (and of US television programming) by substantially lengthening the school day, the US National Science Foundation (NSF) announced a pilot project to revamp science education in nine cities, each of which will receive $\$ 15$ million over five years (see page 87). On top of that, Bruce Alberts, the molecular biologist in his first year as president of the US National Academy of Sciences, has declared improved science education nationwide to be one of his most important goals; he is exploring several ways in which the academy can engage scientists in teaching in local school systems. (With an impressive project along these lines in San Francisco to his personal credit, he is exploring ways of directing the academy's intellectual talent into new approaches to teaching science.) And the Howard Hughes Medical Institute, which spends most of its money on research, is also supporting innovative science programmes at undergraduate colleges.

So are we back in the Sputnik days, when fears of Soviet domination in space prompted a huge investment in science and mathematics curricula? Hardly. That was made to seem a crisis, but the National Education Commission's report shows that present difficulties have their roots in longestablished attitudes to schooling and to education generally. In any case, the threat now is industrial competitiveness. And for what it is worth, the United States is not alone in its sense of being educationally deprived; only this week, the British government has been fine-tuning its national curriculum (and paradoxically making sports compulsory for 14-16 year-olds.) The worry is that competitors elsewhere have been investing in excellent elementary and secondary education for decades past, and are now reaping the benefits. Will the newly discovered laggards have the stomach for the long haul ahead of them?

\section{Crick on consciousness}

The London Times is in two minds on its sponsorship of a reductionist occasion.

THE opening sentence of J. D. Watson's book The Double Helix may be aptly paraphrased as "Nobody has ever known Francis Crick to write a dull book". For Crick's latest book is predictably far from dull (see R. L. Gregory, Nature 368, $359 ;$ 1994). The Astonishing Hypothesis, subtitled "the scientific search for the soul" (Scribner's, New York, \$25.00; Simon \& Schuster, London, £16.99), has inevitably caused a stir. In Britain, The Times has arranged with Dillons, the booksellers, that Crick should engage in a public debate at Westminster Central Hall, London, on 25 May. (Tickets cost $£ 10$ from The Times/Dillons Science Forum, Dillons, 82 Gower Street, London WC1 6EQ). But many must now wonder whether The Times is having second thoughts.

The book is about the relationship between mind and brain. Its essential message is that the collection of neurons with which the insides of our heads are endowed is an adaptive, 'self-organizing' system whose hard wiring is the product of evolution, but which is to some extent still malleable at birth. The machine is somehow able to make sense of the real world outside as well as of the inner world of personal consciousness. The precise attributes of the neuronal ensemble responsible for consciousness are not yet, of course, known. But that is more or less all there is to say about mind/ soul and brain, although at present there is only a rudimentary understanding of what happens within the skull.

So the hypothesis is not particularly astonishing. Certainly it will not have astonished Crick himself. But there are many, to whom the hypothesis is at least mildly shocking. In a leading article on Monday (9 May), the newspaper predictably sets out to put some water between itself and the astonishing hypothesis. Consciousness is the stumblingblock. Both Descartes and Samuel Johnson are quoted as sources of the belief that conscious thought (not to mention soul) has no material correlates. The newspaper says that "only' when the details are worked out can we be sure the reductionists are right" and, a little wistfully, that "proving it may turn out to be a long and difficult task". Many no doubt hope that the prediction is correct.

Consciousness is indeed the central issue, but Crick has himself gone a long way to describe the terms in which the concept can be discussed. The brain is not a kind of electronic computer, or something with analogues in artificial intelligence, but all these things and more, as well as being able to keep a retrievable record of its affairs. The immediate task is to enumerate those functions. But the adaptive value of cognition, especially in presenting those who practise it with a choice between alternative courses of action not necessarily dictated by the endocrine systems, is manifestly so great that the question is not whether consciousness can conceivably be the product of natural selection, but whether natural selection could have failed to single it out. The surprise is that neurons are such versatile cells. 